\title{
Rethinking home as a node for transition
}

\author{
Pernilla Hagbert \\ [KTH Royal Institute of Technology, Stockholm, Sweden]
}

Home constitutes a key part of the everyday, the mundane and familiar, but also provides a basis for our aspirations and visions of what kind of life we wish to lead - and by extension, what kind

of society we construct. How we construct home (physically, socially, and cognitively), as part of how we conceive our relation to society and the planet, has significant implications for the social and environmental impact of residential development.

A critical understanding of the domestic, and the potential of the everyday, has been recognised in calls for both local and society-wide transitions from a perspective of the 'home front' (Gibson-Graham 1993; Astyk 2013), and proposes going beyond the four walls of the private dwelling to acknowledge the diverse transformative practices needed to challenge dominant norms and lock-ins. The perspective put forward in this chapter emphasises housing for degrowth as rejecting Western bourgeois and consumerist representations of home, and instead presents alternative housing practices, with examples from Sweden, which challenge a high-consuming culture of indebtedness and neoliberalisation of housing, and that reimagine home as a collaborative, decommodified and feminist engagement with people and place, and as a node for transitions to a low-impact society.

\section{Finding home}

The notion of home has been a well-explored topic in Western poetry, music and literature throughout the last centuries. Just one of many examples is the stanza from the early $19^{\text {th }}$ century song "Home, Sweet Home” by American lyricist John Howard Payne:

"Mid pleasures and palaces though we may roam, be it ever so humble, there's no place like home." 
This type of romantic depiction of home as a geographical, but also spiritual resting place, is perhaps one of the most common associations and conceptualisations of home in Western popular culture. Yet this concept of home is neither unproblematic in its bourgeois assumption and imperialist heritage, nor is it necessarily the dominant framing in today's representation of home as embedded in consumer society. So how could the very idea of home be critically examined, and reconceptualised, as a way of approaching the inherent proposition of immaterial values and humbleness expressed in the lyrics above, challenging the material-intense manifestations of modern ways of living?

While a deeper etymological inquiry is not the primary focus here, the terms used to define home over the centuries are relevant to address in trying to examine also current conceptualisations. The English word home can be traced back through early Germanic forms, where Brink (1995) connects it both to meanings such as world, country, farm, village, camp, resting place and lair signifying a connection to place and settlement - and to notions of family, household servants, love and marriage - as both affection and the practical arrangement of everyday life. The semantic connection to fire, illustrated for example by the mythology of Hestia, the Greek goddess of home, hearth, family, domesticity and architecture (Moore 2000), further underlines home as connected to place and the need for shelter, but also encompasses the social codifications and community constructed around the hearth.

With Western imperialism and industrialisation - particularly the rise of coal combustion and steam power - the localisation of production became less bounded by local natural landscape prerequisites and instead lent itself to a rationality of market exchange and centralising labour in urban settlements (Malm 2014). Moore (2000) further notes a 'domestication' of the word home during this urbanisation, as the pre-industrial meaning signifying birthplace or native environment shifted to refer more narrowly to the family dwelling or house. The home came to represent new economic and socio-technical ideals of an emerging middle class, with bourgeois notions of home and domesticity being associated with aspects of intimacy, privacy, seclusion, and the sanctity of property. These normative understandings have shaped how Western urban residential environments have developed, yet have nonetheless been far from the reality in 
overcrowded working class living conditions, whether in $19^{\text {th }}$ century industrialised England, early $20^{\text {th }}$ century Sweden or $21^{\text {th }}$ century marginalised communities across the globe.

\section{Home as a political agenda}

As industrialisation moved much of the economical (male) interests from the home to the industrial sphere, the home as such has at times been a less explicit issue on the political agenda instead often invoked as an aggregated 'housing issue'. Mixing politics and home life has been regarded with caution, seen as a private affair rather than a matter of public policy. Yet normative assumptions of what constitutes as good or poor moral, in keeping a good or poor home and home life, has nonetheless abounded, and has shaped policies and ideological framings of residential culture, household configurations and meanings of home as part of the structuring of society. In the portrayal of women as the harbingers of 'homeliness', the home can for example be seen as having been both restrictive and empowering (Rybczynski 1986), reproducing social norms of what it means to be a good home-maker, while also providing a (private) domain for women - yet imbued with social hierarchies and patriarchal oppression.

The more direct political potential of the home was nonetheless actualised during the late $19^{\text {th }}$ and early $20^{\text {th }}$ century as part of understandings of modernity and democracy. Not the least in the shaping of the modern Western welfare state, the political rhetoric of home can be exemplified in the Swedish Social Democratic notion of a 'People's Home' in the 1930's. Within this framing, the private was indeed made into public policy, with the idea of 'good housing for all' being underlined by the ideological premise of a good resident as a productive citizen, ensuring personal freedom through collaborating in building up the country (Hård 2010).

In the era of individualisation and globalisation that has since ensued, the debate regarding to what extent home can be considered a private or public political matter has now become in essence the same issue it was a century ago. Since the deregulation of the Swedish housing sector during the 1980's and 90's (Hedin et al. 2011), the market - as in many other countries - has to a greater extent steered housing development. In a results-oriented neoliberal view, the perceived subjectiveness of home is reduced to individual preferences assumed to be met through the 
market, yet the concept of home represented in this market understanding tends to be streamlined and prescriptive in its framing towards a specific target group - the urban 'creative' middle class.

\section{The commodification of home}

Concepts of home are, as mentioned above, entangled with normative ideas of what constitutes a 'good life'. Underlying assumptions of modernity and comfort, but also control, need to be examined in the resource-intensity of mainstream residential development, and the consumptionfocused framing of what it means to live well in a capitalist society. The commodification of home as a 'product' to be purchased and sold should further be understood as part of an increased speculative financialisation of housing and continued emphasis on home-ownership (Forrest 2015), but also relates to the 'lifestylification' of home and everyday life.

The framing of housing as a commodity is underlined by the interlinkage of mortgage systems and speculative global finance. Fostering an unsustainable debt culture, the home is framed as an investment, which in turn relies on and reproduces dominant economic and social structures that tie people into a growth dogma. The ideal of home-ownership is part of social, political and economic norms surrounding the control over one's private domain, something that defines and validates you and your accomplishments as a 'responsible citizen' (Smith 2015). The notion of a housing career, as making a profit of living and constantly 'trading up', is within this logic lauded as smart and responsible. In this view, the private right to property dominates over the human right to housing. This in turn sees the reduction of residents to either owners or tenants. The idea of home as being linked to private ownership, perpetuated in both popular media and political rhetoric, also supposes that people who have not personally invested (understood as having a financial stake) in their place of residence are less attached, and thus less engaged as residents or neighbours. Yet the relation between home ownership and place attachment, or feelings of 'athomeness', has been found to be rather weak (Windsong 2010).

The commodification of home moreover prescribes certain patterns of living, underlining a prevalent valuation of time and space, and the role home plays in shaping our assumptions of ourselves. Beyond providing a shelter over one's head, the need for home entails aspects of socialisation and self-expression (Lawrence 1987), the latter being increasingly co-opted in the 
equation of home, lifestyle and consumerism. From the perspective of the housing sector, residents are assessed based on their willingness-to-pay and segmented into specific market groups. As an emotional, social or restorative 'product', the home comes to serve as a marker of social status and of identity - a symbol of the cultural or financial capital associated with particular neighbourhoods and housing typologies (Gram-Hanssen and Bech-Danielsen 2004; Hauge and Kolstad 2007). In this rationale, home becomes an object onto which more and more stuff can be added in the technological development of domestic environments and artefacts.

The modernist idea of the home as a machine - which continues to influence a now increasingly globalised residential development - moreover reduces the relationship between notions of home and the (productive and reproductive) nature of household work to a techno-centric focus on the ability to manage household tasks as swiftly and conveniently as possible. Still, the gender divide in time spent on household work - and the undervaluation of the labour of other bodies in producing the artefacts and goods consumed - underlines a patriarchal and imperialist approach to the Western domestic ideal, where the resource and labour intensity of a comfortable home is seen as an externality. In this view, a 'greener' way of living is translated into consuming more efficient products or services (shifting domestic work further away from the home), rather than fundamentally challenging the conceptualisation of home and the socio-ecological implications of contemporary housing practices.

\section{Reconceptualising home as part of degrowth transitions}

Acknowledging the notion of home as part in shaping our connection with people and place, and the organisation of everyday practices, means we need to recognise the role home might play in transitions to a low-impact society (Hagbert 2016a). With the failures of mainstream, growthoriented housing development to provide healthy, affordable and meaningful living environments, more and more people are seeking ways of living that are less resource intensive and more diverse - including living smaller, simpler and sharing spaces and resources. In conceptualising a more sustainable manifestation of home, a key aspect is seeing the dynamic of 'degrowing home', beyond a neoliberal view on individual residential preferences and commodification. The home encompasses both cognitive aspects of what constitutes a good life, which will need to be re-imagined, and a practical reality of being a central node for daily life, 
where alternative patterns of practices will need to be enabled. The possibility to see home as a node for more radical societal transformations is thus dependent on reconceptualising home both in the built environment and in the mind.

The home is in this perspective placed as a crucible between society and the individual, demanding both a critical framing of agency, as well as more structural changes in the provision of not only housing - as a commodity or as a building - but of living environments. As a platform for engaging in low-impact degrowth practices, the home is set as a starting point for change, which bridges the segmentation of home life from other areas of society. Here, the metaphor of the node proposes a shift in mind-set from what is commonly portrayed as delimited policy arenas to what could be a more useful way of imagining everyday life as interconnected both in spatial and social terms. Situating home as part of constructing alternative social and feminist ecologies, rather than relying on mainstream stories of growth and technological innovation, will also consider 'doing home' in different ways.

By exploring attitudes towards and engagements in alternative housing practices (as explored by Hagbert 2016b, and Hagbert and Bradley 2017), another way of conceptualising home, that challenge current housing market logics, emerge. This can be seen as 're-politicising' home, beyond any blanket solution to 'housing issues' - as suggested by either the market or standardised state-driven housing provision - and instead emphasises a diversity in approaches, situated in the everyday. By putting other aspects into practice, the focus is shifted from the intertwined economic interests of urban and residential development, to potentially new ways of organising life, and what one can do in and from the basis of the home. The following sections examine practical examples of what home could mean in a degrowth, low-impact future, based in empirical insights from alternative housing practices and projects in Sweden that explore more collaborative, self-sufficient and convivial home practices.

\section{Autonomy through collaboration}

One key aspect in the formulation of alternative, low-impact conceptualisations of home is the critical examination of an individualistic neoliberal urban development and reliance on largescale technical systems that alienate residents from each other (paradoxically often within an 
increasingly densified urban environment), and from ecological systems. There are several examples of housing ideas and projects that challenge this, instead seeking a development characterised by self-management and re-connection with people and place, such as eco-villages and co-housing initiatives (Chatterton 2013; Vestbro and Horelli 2012), or various selfsufficiency and self-build initiatives (Hagbert and Bradley 2017; Seyfang 2010).

These types of ideas often acknowledge the agency of residents, not as consumer or 'end users', but as actors in their own right, in together creating the premise for a resilient local community. Particularly in the context of countries such as Sweden, with a high household indebtedness, a large number of single-person households and an aging population, the potential of organising alternatives to an increasingly isolating urban experience within a less and less attainable housing market is recognised. Initiatives to create more diverse living environments have developed, focusing on for example sharing (rather than competing for) spaces, knowledge and resources.

Calls for re-ruralisation and re-localised production, which challenge an eco-modernist approach of further centralisation and densification, are part in the strive for independency from an urban growth economy. In this perspective, home is not primarily seen as a financial investment within the speculative market, but as the basis for a type of community-building that invests in another kind of growth altogether. As expressed by a woman who left suburban life to transition to a post-carbon way of living in a semi-rural municipality in western Sweden, there is a potential in building a community and way of life that goes beyond simply 'waving to the neighbours' over the suburban fence, while keeping jobs just to pay a mortgage and purchasing everything needed for one's sustenance. A key motivation that emerged in empirical studies with Swedish households engaging in transitions in some way (Hagbert and Bradley 2017), is selfmanagement. This is underlined by a desire to provide for one's own needs, yet acknowledges the inter-dependency and need for collaboration between neighbours.

While the notion of home as a 'man's castle' is a prevalent analogy to signify control (and a patriarchal reign), a more collaborative view on the home means embracing also the struggles of negotiating shared practices and spaces. Sandstedt and Westin (2015) for example describe Swedish co-housing life as going beyond the dichotomy of Gesellschaft and Gemeinshaft in 
mediating between the strive for personal independence and the reciprocity of the co-housing community. Co-housing projects have however also been criticised for the risk of selfsegregation and the tendency for social and ethnic homogeneity among residents (Chiodelli and Baglione 2014), pointing to the need for more inclusionary practices regarding aspects such as who gets to take part in shared activities and spaces, and at what scale this collaborative effort is aimed. As for example described by a young female housing activist and resident in a newly built co-house in the Southern Swedish city of Malmö, the use of a shared kitchen and dining space can (and should) go beyond serving the direct co-housing community (where they cook communal meals twice a week), to also provide a platform for urban activism and opening up the space for various social or cultural activities.

Handling conflicts that might (and will inevitably) emerge in living with others - as part of society at large, or a particular community - demands daring to see home also as a conflicted experience, and acknowledging the voices of others. This however also proposes opportunities for exploring 'new' forms of collective decision-making that challenge a top-down authoritarianism of the home as being ruled by a (male) 'head of the household'. An example can be found in an older, retrofitted Swedish co-house in Stockholm, where a more informal forum for discussion (outside of the regular house meetings) is based on the couch as a democratic gathering point. Issues that arise as part of everyday life are brought up as 'couches', meaning a literal meeting on one of the couches in the shared spaces of the house, where everyone in attendance is free to say whatever they want and not be judged. By negotiating individual positions in relation to the collective, compromises are situated in regards to the benefits, but also limits, of collaboration, and the resources and labour available to satiate different needs at different times.

The formulation of home as both autonomous, self-sufficient and a shared experience of everyday life challenges conventional representations of home as an individualistic endeavour within a (nevertheless conformist) consumerist frame. It instead follows an understanding of autonomy as a collective project (Deriu 2014). Valuing the care of people and place not as a service to be purchased, but as commonly created. 


\section{Conviviality and self-sufficiency}

Rather than seeing the dwelling as an object, a commodity, alternative housing practices can also frame home as a more convivial space. As both an arena and a tool for transitions, the relationships between residents and their home environments emphasise lay (or situated) knowledge and interpretations rather than expert top-down planning. Employing a transformative understanding of housing for degrowth positions residents as co-creators of their homes. As agents of change, the processes surrounding housing development can be challenged altogether by residents engaging in practices that entail reskilling and shared learning in aspects of design, construction and maintenance. By redistributing the role and power of the landlord or property owner, residents are finding different ways to re-engage with the ongoing process of making home as not only a cognitive or consumerist act, but as a bodily, physical experience.

Also within the completely ordinary but abundant existing residential stock that will have to be reinvented in a low-impact future, people are forming their lives and communities in spite of current structures. For example, both rural villages and large-scale modernist multi-family suburbs (both left to their demise in an urbanised economy) are being reinvigorated into transition hubs. As an example of the first, the small village of Uddebo ${ }^{1}$ in Western Sweden has over the past decade seen an influx of people seeking affordable, low-impact or even off-grid housing solutions. Based in a vision of 'play, experimentation and community', the projects range from refurbishing an old weaving factory into workshops, art studios and meeting places, creating space for musical venues in old abandoned buildings, to forming a local co-op, building a village sauna, a bike kitchen and a community garden. Through low land costs, and housing experiments such as tiny houses, people can significantly lower their cost of living and downshift from the formal economy to further engage in the variety of activities surrounding music, theatre, art, politics, crafts and agriculture being developed. While there is a risk that such 'back-to-theland' initiatives often consist of creatives and people with cultural (if not necessarily financial) capital, the convivial premise of these types of communities nonetheless often provides an openness to a pluralism of cultural expressions and experimentation as 'trying by doing' rather than prescribing certain forms and frameworks of living - as can be the case in both conventionalist suburbia and other 'alternative' intentional communities.

\footnotetext{
${ }^{1}$ See www.uddebo.se
} 
These types of practical, alternative examples propose a different way of structuring housing development, often driven by residents themselves in either co-building or retrofitting older buildings to enable functions that might have been lost in new market-driven housing, but also in providing opportunities to re-evaluate the very understandings of everyday life and the practices one can engage in within the existing environment. In the project HOPP, in the area of Hökarängen $^{2}$ south of Stockholm, local residents re-claimed the story of the stereotypically marginalised suburb to instead co-create a vision for a post-carbon, post-growth future, 'inspiring action'. They did so for example through integrating urban agriculture (based in permaculture principles) in, and adjacent to the modernist housing structures, rejecting the narrative of the green spaces in-between the buildings as being unproductive or as needing further densification. By challenging the functionalist segmentation of these types of housing areas as passive 'bedroom suburbs', but also the current prevailing neoliberal commercialist notion of the 'mixed attractive city', residential environments are re-imagined as spaces for production in building local resilience and self-sufficiency.

Conceptualising home as a site for re-localised production, integrating multiple functions rather than the spatial and social segmentation of everyday life, proposes challenging the dwelling as functionally determined, where the layout of the living environment prescribes certain practices. In seeing the home as a node for transition, the very organisation of the home will need to facilitate experimentation, reskilling and conviviality. This in turn demands space that is both accessible (that is, non-commercial) and available to change (not already scripted or spatially organised as to allow only a certain programming). In this sense, the open-floor plan apartments being built in new urban developments as part of a consumerist 'lifestylification' does not offer the supposed flexibility. The activities imagined to take place are limited to dinner parties or watching TV, rather than spaces for experimenting.

Enabling self-expression through meaningful practices rather than objects entails breaking with normative residential design ideas. In examples from both co-housing and other alternative housing developments, the negotiation of space for activities such as woodworking, sewing,

\footnotetext{
${ }^{2}$ See www.hoppbloggen.com
} 
childcare, but also for decision-making, political discussions and activism are integrated into the home environment at different scales. Instead of a clear delimitation of spaces, as in the bourgeois urban home - controlling a series of thresholds, from the neighbourhood to the entrance gate to the apartment door - the everyday practices of degrowth are less spatially bound, and opens the home up for collaboration, rather than enclosure.

\section{Feminist re-imaginations of everyday life}

Work-centric growth societies (where work is understood precisely as being external to and separate from the home) tend to supress time for family, community and political activities (Schor 2014). In the strive for a simpler, more convivial and self-sufficient way of life, the role of 'work' in relation to home is also being reassessed, be it through downshifting in the number of hours per day spent in an office, or working from the basis of one's kitchen, living room or various neighbourhood spaces to provide goods and services that offer alternatives to massproduction and consumption. In challenging the privatised dwelling, a more participatory approach to housing also suggests cultivating 'public time', in sharing spaces, time, and the work involved in upholding home and daily life as a collective engagement (Jarvis 2011). More collaborative forms of living might also challenge traditional household configurations and gender norms (as explored by among others Vestbro and Horelli 2012), with the potential to renegotiate social relations and aspects of for example child-rearing as part of a common undertaking (Wasshede 2017).

While today largely replaced by simplistic market surveys conducted by private developers, the rigorous domestic research done during the $20^{\text {th }}$ century focused on gaining an understanding of the everyday, and particularly built upon the rich, situated female knowledges and experiences embedded within the practices and (re)productive work of home life (outlined e.g. by Åkerman et al. 1984). The formulation of co-housing manifestos and programs during the 1970's and 80' (such as the 'live in community' idea - 'bo i gemenskap', or BIG for short - proposed by a group of women as a model for organising housing communities through among other things self-work) rejected the separation of productive and reproductive work, and the modernist idea of minimising and rationalising household tasks (Vestbro and Horelli 2012). Acknowledging that women's (often un- or undervalued) work within the home provides a valuable contribution to 
society demands a different valuation also of the knowledge associated with these types of practices. Rather than being tedious and mindless, the skills and know-how involved in what has traditionally been gendered as 'female' household tasks or 'home-making' (Darke 1994) simply emphasise other ways of knowing and doing.

Beyond assumptions of, and the search for, universal theories or systems for radical transformation, the home can in this perspective provide a basis for feminist re-imaginations of everyday life, drawing upon for example Haraway (1988) and Gibson-Graham (2008) in considering situated knowledge among diverse groups (women as well as non-western "others"). Conventional notions of home practices are challenged by the myriad of ongoing local transitions that put home at the centre of societal transformations (Astyk 2013). Communities across the world are already engaging in non-consumerist practices and a reconnection with place (GibsonGraham 2008; 2011). The 'mundane' is in this perspective made political, where mending socks or making jam is (often tongue-in-cheek) framed as acts of non-consumerist resistance, and where cooking communal dinners or inviting strangers to dine transforms a kitchen table into a platform for cultural exchange - as in the case of the Swedish 'Invitational Department' (Invitationsdepartementet ${ }^{3}$ ) connecting fluent Swedish-speakers with newly arrived immigrants to promote a 'society where we meet as people, talk and build relationships', from the humble basis of one's home.

\section{Conclusion}

As explored in this chapter, concepts of home - as a mediation between the individual and society, between the everyday and aspirations for what kind of life we want to live - are relevant to critically examine both in relation to understanding the assumptions and norms inherent to a contemporary unsustainable housing development, and in the formulation of degrowth futures. By rejecting a Western (but increasingly globalised) bourgeois and consumerist representation of home, housing for degrowth will need to explore alternative conceptualisations and practices of 'doing home'. Exploring the ways in which home is implicitly and explicitly political, might provide a different starting point in thinking about transitions to low-impact societies as situated in the everyday, where home is an ongoing process and not a product or simply a showcase for an

\footnotetext{
${ }^{3}$ See www.invitationsdepartementet.se
} 
individualised lifestyle. Re-politicising home also means we need to embrace the messiness of this process, where new forms of collective decision-making among people as inter-dependent neighbours and communities, acknowledged as actors in their own right, replace the top-down relationship between landlords and tenants, or the speculative transaction between housing developers and home-buyers.

This chapter has offered a few examples from housing practices and projects in Sweden that reimagine a decommodified, collaborative and feminist conceptualisation of home. When discussing how key degrowth ideas are being explored in practice, the different perspectives described here emphasise only some of what should be understood as a diverse range of transformative practices that cut across any single concept or solution, but that propose alternatives to a mainstream growth-oriented urban development. This includes seeing home as a basis for autonomy and self-management, but at the same time inclusion. A space for experimentation, reskilling and for sharing both spaces and knowledge, and a place for embracing the everyday as convivial and collaborative, rather than segmented, gendered and hierarchic. The humble potential of home lies precisely in the cross-section between physical, social and cognitive constructs of 'the good life'. Enabling a more sustainable housing development cannot simply be a question of providing more of the same - generic residential developments that lock people into inherently unsustainable structures - but underlines the need to rethink home as an evolution of our connection to people and to place, providing sustenance rather than demanding it, and as a node for transitions to a low-impact society.

\section{References}

Astyk S. (2013) Depletion and Abundance: life on the new home front. Gabriola Island, B.C.: New Society Publishers.

Brink, S (1995) 'Home: The Term and the Concept from a Linguistic and Settlement-Historical Viewpoint' in Benjamin D. and Stea D. (eds) The Home: Words, Interpretations, Meanings and Environments. Aldershot: Avebury, 17-24. 
Chatterton, P. (2013) 'Towards an Agenda for Post-carbon Cities: Lessons from Lilac, the UK's First Ecological, Affordable Cohousing Community', International Journal of Urban and Regional Research 37(5), 1654-1674.

Chiodelli, F. and Baglione, V. (2014) 'Living together privately: for a cautious reading of cohousing', Urban Research \& Practice 7(1), 20-34.

Darke, J. (1994) 'Women and the meaning of home' in Gilroy, R. and Woods, R. (eds) Housing women. London: Routledge, 11-30.

Deriu, M (2014) 'Autonomy' in D'alisa G., Demaria F. and Kallis G. (eds) Degrowth: a vocabulary for a new era. New York: Routledge, 55-58.

Forrest R. (2015) 'The ongoing financialisation of home ownership - new times, new contexts', International Journal of Housing Policy 15(1), 1-5.

Gibson-Graham, J. K. (1993) 'Waiting for the Revolution, or How to Smash Capitalism while Working at Home in Your Spare Time', Rethinking Marxism 6(2), 10-24.

Gibson-Graham, J. K. (2008) 'Diverse economies: performative practices for "other worlds", Progress in Human Geography 32(5), 613-632.

Gibson-Graham, J. K. (2011). 'A feminist project of belonging for the anthropocene', Gender, Place and Culture 18(1), 1-21.

Gram-Hanssen K. and Bech-Danielsen C. (2004) 'House, home and identity from a consumption perspective', Housing, Theory and Society 21(1), 17-26.

Hagbert P. (2016a) A sustainable home? Reconceptualizing home in a low-impact society. $\mathrm{PhD}$ Thesis: Department of Architecture, Chalmers University of Technology. 
Hagbert P. (2016b) '“It's Just a Matter of Adjustment": Residents' Perceptions and the Potential for Low-impact Home Practices', Housing, Theory and Society 33(3), 288-304.

Hagbert P. and Bradley K. (2017) 'Transitions on the home front: A story of sustainable living beyond eco-efficiency', Energy Research \& Social Science 31, 240-248.

Haraway, D. (1988) 'Situated Knowledges: The Science Question in Feminism and the Privilege of Partial Perspective', Feminist Studies 14(3), 575-599.

Hauge A. L. and Kolstad A. (2007) 'Dwelling as an expression of identity. A comparative study among residents in high-priced and low-priced neighbourhoods in Norway', Housing, Theory and Society 24(4), 272-292.

Hedin K., Clark E., Lundholm E. and Malmberg, G. (2011) 'Neoliberalization of Housing in Sweden: Gentrification, Filtering, and Social Polarization', Annals of the Association of American Geographers 102(2), 443-463.

Hård M. (2010) 'The Good Apartment: The Social (Democratic) Construction of Swedish Homes', Home Cultures 7(2), 117-133.

Jarvis, H. (2011) 'Saving space, sharing time: integrated infrastructures of daily life in cohousing', Environment and Planning A 43(3), 560-577.

Lawrence R. (1987) Housing, Dwellings and Homes: Design Theory, Research and Practice. Chichester: John Wiley \& Sons.

Malm A. (2014) Fossil Capital: The Rise of Steam-Power in the British Cotton Industry, c. 18251848, and the Roots of Global Warming. PhD Thesis: Department of Human Ecology, Lund University. 
Moore J. (2000). 'Placing Home in Context', Journal of Environmental Psychology 20(3), 207217.

Rybczynski W. (1986) Home: A Short History of an Idea. New York: Penguin.

Sandstedt, E. and Westin, S. (2015) 'Beyond Gemeinschaft and Gesellschaft. Cohousing Life in Contemporary Sweden', Housing, Theory and Society 32(2), 131-150.

Schor J. B. (2014) 'Work sharing' in D'alisa G., Demaria F. and Kallis G. (eds) Degrowth: a vocabulary for a new era. New York: Routledge, 195-198.

Seyfang, G. (2010) 'Community action for sustainable housing: Building a low-carbon future', Energy Policy 38(12), 7624-7633.

Smith S. J. (2015) 'Owner occupation: at home in a spatial, financial paradox', International Journal of Housing Policy 15(1), 61-83.

Vestbro, D. U. and Horelli, L. (2012) 'Design for Gender Equality: The History of Co-Housing Ideas and Realities', Built Environment 38(3), 315-335.

Wasshede, C. (2017) 'The Child of the Common: Governing Children in the Freetown Christiania, Denmark', Children \& Society 31(5), 403-413.

Windsong E. A. (2010) 'There is no place like home: Complexities in exploring home and place attachment', Social Science Journal 47(1), 205-214.

Åkerman, B. et al. eds (1984) Kunskap för vår vardag: forskning och utbildning för hemmen. Stockholm: Akademilitteratur. 